\title{
Correction to: The emergence of phase asynchrony and frequency modulation in metacommunities
}

\author{
Frederic Guichard ${ }^{1}$ (D) Yuxiang Zhang ${ }^{2} \cdot$ Frithjof Lutscher $^{3}$
}

Published online: 29 December 2018

(C) Springer Nature B.V. 2019

\section{Correction to: Theoretical Ecology https://doi.org/10.1007/s12080-018-0398-8}

The original version of this article unfortunately contained a mistake. The name "Yuxian Zhang" should be corrected to "Yuxiang Zhang".

The original article was corrected.

The online version of the original article can be found at https://oi.org/ 10.1007/s12080-018-0398-8

Frederic Guichard

frederic.guichard@mcgill.ca

1 Department of Biology, McGill University, 1205 Docteur Penfield, Montreal, Quebec H3A 1B1, Canada

2 School of Mathematics, Tianjin University, Tianjin, China

3 Department of Mathematics and Statistics \& Department of Biology, 585 King Edward Avenue, Ottawa, Ontario K1N 6N5, Canada 